\title{
Sobre la «primera crisis religiosa» de san Agustín
}

\section{IN LONGINQUAM REGIONEM}

La conversión de san Agustín se inscribe entre las que presentan dos fases: una, de alejamiento hasta el abismo del error; y otra, de retorno hasta el feliz encuentro con la verdad ${ }^{1}$. En estas páginas me propongo describir un trozo de la primera, aquel en que se recoge la crisis religiosa comprendida entre los iniciales devaneos infantiles y la lectura del Hortensius. Cierto es que al argumento general han venido muchos autores, que resulta de forzoso análisis en las biografías rigurosas y que, no obstante, se suele incidir más en la segunda ${ }^{2}$. Pero no es menos verdad que su riqueza aleccionadora sigue vigente en estos tiempos finiseculares, y que al celebrar el $X V I$ Centenario de la

1. «A travers les exclusives de ce qu'on pourrait appeler l'aventure de la contradiction comme à travers les surprises de ce qu'on pourrait appeler l'aventure de l'aversion, se préparait la logique de ce qu'est l'aventure de la conversion» (A. MANDouze, Saint Augustin. L'aventure de la raison et de la grâce, Paris 1968, 718). Entre san Agustín y san Pablo lo mismo que entre san Agustín y Newman existen al respecto, claras semejanzas (P. LANGA, John Henry Newman o el «Augustinus Redivivus»: RelCult 25 [1979] 529-566). También diferencias, pues ni en san Pablo ni en los convertidos llegados a este mundo en el seno del error es posible hablar de alejamiento de la fe. San Agustín, por el contrario, recibe desde el primer momento educación cristiana de su piadosa madre santa Mónica: «Siendo todavía niño oí ya hablar de la vida eterna...; y fui signado con el signo de la cruz, y se me dio a gustar su sal desde el mismo vientre de mi madre, que esperó siempre mucho en ti» (Conf. I, 11,17: BAC 11/II (5. a edic., Madrid 1968, 88; III, 4, 7-8; cf. A. Trape, Sant 'Agostino. Mia Madre, Milano 1975; M. Larrinaga, Santa Mónica, Madrid 1986; H. RondeT, Miscellanea augustiniana. La croix sur le front: RSR 42 [1954] 388-394).

2. San Posidio la pasa completamente por alto (VA, 1), y Jesús Burgaleta, al abordar la prehistoria de la conversión en su excelente estudio, omite detalles de interés, aunque algunos figuran antes, en la primera parte (47-91): cf. La conversión es un proceso (En las Confesiones de san Agustín) Instituto Superior de Pastoral, Salamanca 1981 (abund. bibl.: 247-268); A. TRAPÈ, San Agustín: Patrología III. La edad de oro de la literatura patrística, BAC 422, Madrid 1981, 412-413. 
Conversión de san Agustín parece oportuno casi necesario, recordarla, máxime teniendo en cuenta que el papa no cesa de insistir en la evangelización de la juventud, con la que tanto tiene que ver la pedagogía agustiniana de esta crisis ${ }^{3}$.

La facilidad y rapidez con que san Agustín abrazó el maniqueísmo - facile ac diebus paucis ${ }^{4}$ - sigue abriendo interrogantes y dividiendo a la crítica ${ }^{5}$. De momento dejemos sentado que constituye un hito significativo, el que más si se me apura, de aquel dispersivo itinerario hacia el error, pero anticipemos igualmente que no es el único, pues son asimismo relevantes los años de adolescencia ${ }^{6}$, la lectura del Hortensius ${ }^{7}$, la consulta del autosuficiente retórico a la Biblia ${ }^{8}$, y los tumbos de nuestro joven protagonista llamando a las puertas de escépticos, matemáticos y neoplatónicos ${ }^{9}$. Enjuiciar, pues, este des-

3. Recordar al Agustín de estos años críticos puede servir de ayuda para no pocos jóvenes hoy tan desorientados como él entonces. Las Confesiones fueron escritas, al fin y al cabo, para cantar las maravillas de Dios et de bonis et de malis (Retract. II, 32; cf. nota 31), pues «laudable cosa es mantener oculto el secreto del Rey; pero honra mucho también revelar y confesar las maravillas del Señor» (S. Posidio, VA, prólogo: BAC 10/I, 4. ${ }^{a}$ edic., Madrid 1969, 304). Para los discursos del papa a la juventud, cf. JuAN PABLo II, Enseñanzas al Pueblo de Dios 1978 ss. Biblioteca de Autores Cristianos, Madrid 1979 ss.

4. De d. an. 1,1: «Multa enim erant, quae facere debui, ne tam facile ac diebus paucis, religionis verissimae semina a pueritia salubriter insita, errore vel fraude falsorum fallaciumve hominum effossa ex animo pellerentur» (PL 42, 93).

5. A título de selección bibliográfica, cf. CH. BOYER, Essais sur la doctrine de Saint Augustin, Paris 1932, 185; R. Jolivet, Saint Augustin et le néoplatonisme chrétien, Paris 1932, 22-35; J. Guitton, Le Temps et l'Eternité chez Plotin et Saint Augustin, Paris 1933, 99; L. Cilleruelo, Ideario de Agustín durante su época maniqueísta: CDios 158 (1946) 337-350; J.M. LE BLOND, Les conversions de saint Augustin, Paris 1950; M.F. ScIACCA, San Agustín, Barcelona 1955, 28-32, 103; H.I. MARrou, Saint Augustin et l'augustinisme, Bourges 1956, 26ss.; J. MoRÁn, El porqué del Agustín Maniqueo: RelCult 4 (1959) 248-261, 412-429; A. SolignaC, Introduction: Saint Augustin. Les Confessions, BAug 13 (Paris 1962) 82-4, 138ss.; A. Mandouze, Saint Augustin, 95-98; A. Trapè: BAC 422, pp. 410-413; ID., S. Agostino. L'uomo, il pastore, il mistico, Fossano 1976, 61-71; ID., Agostino di Ippona: DPAC I (Marietti 1983) 92; J. RIES, Saint Augustin et le manichéisme à la lumière du livre III des Confessions, en: «Le Confessioni» di Agostino d'Ippona, libri III-V. Lectio Augustini/II, Settimana Agostiniana Pavese, Edizioni «Augustinus»Palermo 1984, 7-26 (=LA); M.G. MARA, La «conversione», e le «conversioni», l'«invito alla conversione» nell' VIII libro delle Confessioni: LA/II, 71-87.

6. Concretamente los de la puericia, referidos en los cc. 8-20 del libro I y en el libro II de las Confesiones. Cf. J. Burgaleta, 50-68; A. SolignaC, 273, 285, 295; L.F. Pizzolato, Il primo libro delle «Confessiones» di Agostino: ai primordi della 'confessio': LA/I, Palermo 1984, 9-78: 9,44ss.; F. De CAPITANI, Il libro II delle «Confessioni» di Sant'Agostino: LA/I, 89-121 (con un lúcido estudio de las monografías completas sobre la vida y obra de S. Ag., y sobre las Confesiones, 90-105).

7. M. TESTARD, Saint Augustin et Cicéron, t. I, Cicéron dans la formation et dans l'oeuvre de saint Augustin, Paris 1958, espec.: La lecture de l'Hortensius, 19-39; A. MANDouze, Saint Augustin, 93-96; A. Trape, S. Agostino. L'uomo, 53-59; J. Ries: LA/II, 8-9.

8. A. Trape, S. Agostino. L'uomo, 62-65; J. Ries: LA/II, 10; cf. los buenos estudios del mismo J. RIES, La Bible chez saint Augustin et chez les manichéens: REAug 7 (1961) 231-243; 9 (1963) 201-215; 10 (1964) 309-329.

9. Aunque los neoplatónicos correspondan ya al viaje del retorno. Cf. A. Trapk, S. Agosti- 
carrío hacia las tinieblas ${ }^{10}$, - aventura de la aversión, escribe Mandouze ${ }^{11}$ sólo desde el infortunado momento en que el futuro vir eloquentissimus ac doctissimus "vino a dar con aquella mujer procaz y escasa de prudencia» que era el maniqueísmo ${ }^{12}$ resulta metodológicamente admisible, no hay duda - y a dicha licencia se acoge este trabajo-, pero equivale a dar por sabidas muchas cosas, si es que no a pasar por alto algunas fundamentales. Por de pronto el fenómeno de la conversión agustiniana constituye un proceso largo, complejo y difícil de analizar ${ }^{13}$, dado que representa una aventura de la razón y de la gracia entretejida de causas y concausas ${ }^{14}$ lo mismo a la ida que a la vuelta ${ }^{15}$.

Que la crisis aquí elegida sea un itinerario hacia la mortalidad de lo carnal

no. L'uomo, 91-96, 123-130; A. MANDouze, Le livre $V$ des 'Confessions' de Saint Augustin: LA/II, 39-55; J.M. Rodríguez, El libro VI de las Confesiones: LA/III, Palermo 1985, 9-44; Mandouze, Saint Augustin, 100-106.

10. Conf. XII, 10,10: «O veritas, lumen cordis mei, non tenebrae meae loquantur mihi! defluxi ad ista et obscuratus sum» (CSEL 33/1, p. 316); VII, 1,2: «sed nondum inluminaveras tenebras meas (Ps 17,29)» (p. 142). El Peregrino de la gracia (Mandouze, Saint Augustin, 46), y como Newman, Misionero y Peregrino de la Luz, describe el pecado como un alejarse de Dios y caminar hacia las tinieblas. Vueltas las espaldas a Dios, que es la Luz, el hombre queda rodeado de tinieblas: cf. Conf. II, 3, 7-8; III, 7,14; 11, 19-20; V, 2,2; VI, 1,1; VII, 7,11; IX, 4,10; XIII, 2,3; 14,15. Sobre el eslogan newmaniano ex umbris et imaginibus in veritatem, epitafio de su tumba por propia voluntad, cf. L. GovaERT, Kardinal Newmans Mariologie und sein persönlicher Werdegang, Universitätsverlag A. Pustet, Salzburg und München 1975, 9, 168 ss.; Cf. L.F. Pizzolato: LA/I, 67 (para el planteamiento concreto en Conf. I).

11. Sobre la aversio y la conversio, cf. De lib. arb. I, 16,35; II, 19,53; P. CAPÁNAGA: BAC/XVI (3. a edic., Madrid 1977) 839; cf. not. 1.

12. De Quant. an. 33,70 (PL 32, 1075); Conf. III, 6,11 (BAC 11/II, 142). El texto latino completo es: «tu autem eras interior intimo meo et superior summo meo. Offendi illam mulierem audacem, inopem prudentiae, aenigma Salomonis, sedentem super sellam in foribus et dicentem: panes occultos libenter edite et aquam dulcem furtivam bibite (Prov 9,17), quae me seduxit, quia invenit foris habitantem in oculo carnis meae et talia ruminantem apud me, qualia per illum vorassem» (CSEL 33/1, p. 53). Nótese la relación entre mulierem audacem y quae me seduxit. El factor seducción cuenta mucho, pues, a la hora de explicar su adhesión al maniqueísmo. Pero a la vez no hay que olvidar la parte precedente del citado texto, donde se hace ver de qué modo contribuyó a ello la sensualidad. Porque fue seducido por el maniqueísmo quia invenit foris habitantem in oculo carnis meae (p. 53), detalle a interpretar por el principio de interioridad a que aluden las primeras palabras del párrafo: tu autem eras interior intimo meo et superior summo meo (p. 53). Pero es que inmediatamente antes ha dicho que pretendió buscar a Dios non secundum intellectum mentis..., sed secundum sensum carnis quaererem (p. 53). La lejanía de Dios, pues, se inicia antes de llegar al Hortensius y se produce a causa de la sensualidad. Sobre deus interior et exterior, buenas reflexiones en R. FLÓREZ, Presencia de la verdad, Madrid 1971, 251-267. En cuanto a maniqueos-hombres carnales, cf. S. Agustín, De mor.man. 19,68: cf. P. Alfaric, L'évolution intellectuelle de Saint Augustin, Paris 1918, 311; P. CourCelle, Le hennissement de concupiscence (homenaje al P. Ángel C. Vega): CDios 181 (1968) 529-534.

13. J. Burgaleta, 12-14, 133 ss.

14. Es el título y la tesis de la ejemplar monografía de A. MAndouze, Saint Augustin. $L$ 'aventure de la raison et de la grace; cf. espec. 11-39, 715-719.

15. «Históricamente su conversión es un acontecimiento extenso en el tiempo y en el espacio, continuado y unitario. Es un espacio biográfico definido y peculiar, largo y homogéneo» (J. Burgaleta, 95). 
y tenebroso lo insinúan imágenes como flumen tartareum ${ }^{16}$, libido ${ }^{17} \mathrm{y}$ caecitas ${ }^{18}$. La religiosidad de la vestidura metafórica responde unas veces a la mitología de los neoplatónicos - por ejemplo, cuando define este volver las espaldas a Dios como un salir fuera de sí mismo ${ }^{19}$ para perderse en la región de la desemejanza: regio dissimilitudinis ${ }^{20}$ - y otras, más a menudo, a la Escritura, ya con los sintagmas regio mortis-regio egestatis ${ }^{21}$, ya mediante alusiones directas a la parábola del hijo pródigo (Lc 15, 11-32), glosada con frecuencia en la predicación ${ }^{22}$ y traída a las Confesiones para ilustrar su propio caso: «apartándome de ti, me marché a una región lejana (in longinquam regionem) para disiparla (mi hacienda) entre las rameras de mis concupiscencias» ${ }^{23}$.

16. Conf. I, 16,26 (p. 23). El «Tártaro» equivale en la mitología religiosa neoplatónica al sentido cristiano de la longinqua regio, o de la regio egestatis de la parábola del hijo pródigo. Cf. III, 1,1: «tartaro libidinis» (p. 44). Cf. P. CouRCELLE, Recherches sur les Confessions de saint Augustin, Paris 21968, 126-128; ID., Les Confessions de saint Augustin dans la tradition littéraire. Antécédents et Postérité, Paris 1963, 74, n. 4; L.F. Pizzolato: LA/I, 67.

17. Conf. III, 1,1: «amare et amari dulce mihi erat magis, si et amantis corpore fruerer. Venam igitur amicitiae coinquinabam sordibus concupiscentiae candoremque eius obnubilabam de tartaro libidinis, et tamen foedus atque inhonestus, elegans et urbanus esse gestiebam abundanti vanitate» (p. 44).

18. Conf. VIII, 4,9: «nonne multi ex profundiore tartaro caecitatis quam Victoribus redeunt ad te et accedunt et inluminantur recipientes lumen, quod si qui recipiunt, accipiunt a te potestatem, ut filii tui fiant? (p. 176); IV, 16,30: «dorsum enim habebam ad lumen et ad ea, quae inluminantur, faciem: unde ipsa facies mea, qua inluminata cernebam, non inluminabatur» (p. 87). Cf. not. 10. Y también In ps. 99,5.

19. Conf. V, 10,18: «et adversus me impietas mea me diviserat» (p. 105); I, 18,28: «nam longe a vultu tuo in affectu tenebroso, non enim pedibus aut spatiis locorum itur abs te aut reditur ad te» (p. 25); II, 2,3; IV, 16,30 (not. anterior); VII, 10,16. Cf. R. FLOREZ, Las dos dimensiones del hombre agustiniano, Madrid 1958, 19-71; ID., Presencia de la verdad, 251-267.

20. Conf. VII, 10,16: «et inveni longe me esse a te in regione dissimilitudinis» (p. 157). En semejanza con esta frase neoplatónica, cf. I, 18,28; In ps. 99,5; 94,1: Véanse P. COURCELlE, Une lecture de Confessions VII, 9,13-21,27: REAug 16 (1970) 106s; G. MADEC, La délivrance de l'Esprit (Confessions VII): LA/III, Palermo 1985, 45-69; L.F. Pizzolato: LA/I, 67; G. Dumeige: DSp III (1957) 1333-1336; P. SINISCALCO: LA/III, 102, not. 61 (abund. bibl.).

21. Conf. IV, 12,18: «beatam vitam queritis in regione mortis: non est illic. Quomodo enim beata vita, ubi nec vita?» (p. 79); II, 10,18: «quies est apud te valde et vita inperturbabilis, qui intrat in te, intrat in gaudium domini sui et non timebit et habebit se optime in optimo. Defluxi abs te ego et erravi, deus meus, nimis devius ab stabilitate tua in adulescentia et factus sum mihi regio egestatis» (p. 43). Cf. A. SolignaC: BAug 13, 689-694; P. CourCelle, Les Confessions, 623-640; A. Mandouze, Saint Augustin, 78, n. 2; L.F. Pizzolato, 67; F. De Capitani, 116-121.

22. Serm. 112 A,2: «Hoc patrimonio accepto filius minor in longinquam regionem profectus est (Lc 15,13): in longinquam, scilicet usque ad oblivionem creatoris sui» (PLS 2,427); Serm. 216,11: «Ille est enim qui convertit aversos» (PL 38,1082); Serm. 96,2; 177,9; 179 A,4; 229 O,2; 344,6 .

23. Conf. IV, 16,30 (BAC 11/II, 185); I, 18,28: «¿Acaso aquel tu hijo menor buscó caballos, o carros, o naves, o voló con alas visibles, o hubo de mover las tabas para irse a aquella región lejana donde disipó lo que le habías dado, oh padre dulce en dárselo y más dulce aún en recibirle andrajoso? Así, pues, estar en afecto libidinoso es lo mismo que estarlo en tenebroso y lo mismo que estar lejos de tu rostro» (BAC 11/II, 99); III, 6,11: «Pero ¿dónde estabas entonces pa- 


\section{DE LA PUERICIA A LA ADOLESCENCIA}

El maduro Agustín de Hipona se confiesa a Dios de haber pecado a tan tierna edad ${ }^{24}$ : son los últimos años escolares de Tagaste ${ }^{25}$, los de gramática en Madaura ${ }^{26}$ y los de universitario bisoño en Cartago ${ }^{27}$. En suma, el período comprendido en los tres primeros libros de las Confesiones ${ }^{28}$. Sobre el Agus-

ra mí? ¡Oh, y qué lejos, sí, y qué lejos peregrinaba fuera de ti, privado hasta de las bellotas de los puercos que yo apacentaba con ellas» (BAC 11/II, 141); II, 10,18: «regio egestatis» (p. 43); IX, 10,24: «ut attingeremus regionem ubertatis indeficientis» (p. 216); IV, 12,18; In ps. 140,2; Serm. 112, A, 2. Cf. A. Mandouze, Saint Augustin, 715ss.; L.F. Pizzolato, 67; 57, n. 213. Cf. B. BluMENKRANZ, La parabole de l'enfant prodigue chez saint Augustin et saint Césaire d'Arles: VigChr 2 (1948) 102-105; A.-M. LA BONNARDIËE, La parabole de l'Enfant prodigue dans les Confessions de saint Augustin: AEPHE 73 (1965) 154-155; P. CourCELlE, Les Confessions, 623-640; ID., Recherches sur les Confessions, 405-440; ID., Augustinus 13 (1968) 135-140; ID., REAug 16 (1970) 271-281; L.C. FERrari, The Theme of the Prodigal Son in Augustine's Confessions: RAug 12 (1977) 105-118; H.J. SIEBEN, Exegesis Patrum. Saggio bibliografico sull'esegesi biblica dei Padri della Chiesa. I.P. Augustinianum, Roma 1983, 75-76; P. SinISCALCO, Le tappe di un itinerario interiore ed esterno del IX libro delle 'Confessiones' di Agostino: LA/III, Palermo 1985, 102, not. 61.

24. Cf. buena colección de textos en J. Burgaleta, 48-57. Cf. también O. TESCARI, Verità e fantasia nella vita di S. Agostino anteriormente alla sua conversione: Augustiniana, Napoli 1955, 63-78; A. Mandouze, 64-81; A. Trape, S. Agostino. L'uomo, 45-51.

25. Hoy Souk-Ahras (Argelia): cf. S. Gsell, Atlas archéologique de l'Algérie (Alger, Jourdan - Paris, Fontemoing 1911), fol. 18, n. 340; P. Brown, Biografía de Agustín de Hipona, Ed. Revista de Occidente, Madrid 1970, 19-30; A. Trape, S. Agostino. L'uomo, 15-35; Cl. LePElley, Les cités de l'Afrique Romaine au Bas-Empire. Tome II. Notices d'histoire municipale, Paris $1981,175-184$.

26. Ciudad de Apuleyo. La metrópoli intelectual donde casi todos los profesores eran paganos, donde cursó estudios secudarios (de gramática) durante cuatro años, concretamente desde los once a los dieciséis años, o acaso mejor a los quince, ya que «en este mismo año (=II, 3,6: decimosexto) se hubieron de interrumpir mis estudios de regreso de Madaura, ciudad vecina, a la que había ido a estudiar literatura y oratoria, en tanto que se hacían los preparativos necesarios para el viaje más largo a Cartago» (Conf. II, 3,5: BAC 11/II, 114-115). Cf. S. Gsell et CH.-A. Joly, Khamissa, Mdaourouch, Announa. Seconde partie, Mdaourouch, Alger, Carbonel-Paris, de Boccard, 1922, 29-34; A. Mandouze, S. Augustin, 68; P. Brown, 43-44; A. Trapè, S. Agostino. L'Uomo, 25-28; Cl. LEPELLEy, II, 127-139.

27. Agustín estudió en Cartago entre el 370 y el 372 (Conf. III, 1-3). Allí volverá desde Tagaste, y como profesor entre el 374 y el 383 (Conf. IV, 7,12; V, 8,14). Ahora interesa su primer contacto con la gran ciudad en los años 370-372. Cf. Cl. LePELLEY, II, 11-53:31ss.

28. La división del libro I de las Confesiones suele ser tripartita: $1{ }^{a}$ ) introducción (cc. 1-5); 2. ${ }^{\text {a }}$ ) años de la infantia (cc. 6-7); 3. ${ }^{\text {a }}$ ) años de la pueritia (cc. 8-20). Así dividen M. Pellegrino, Le 'Confessioni' di sant'Agostino. Studio introduttivo, Roma 1956 (rist. 1972), 27,32s; A. SoligNAC: BAug 13 (Paris 1962) 273,285,295; M. Pellegrino-C. Carena, Opere di sant’Agostino, I, 1. Nuova Biblioteca Agostiniana (=NBA), Roma ${ }^{3}$ 1965, 4,8,16; Pizzolato, 9. El libro II cubre el año decimosexto, transcurrido en Tagaste a la espera de que el padre consiguiera el dinero necesario para afrontar los estudios en Cartago (Conf. II, 2,4; 3, 5-6): cf. F. DE CAPITANI, 105. Los antiguos dividían la vida en siete edades, a las que se atiene el propio San Agustín ( $E p$ 213,1; De ver. rel. 26,48; In ps. 127,15): infancia (hasta los siete años); adolescencia (catorce-veintiocho); juventud (veintiocho-cincuenta); virilidad (cincuenta-sesenta); ancianidad (sesenta-ochenta); decrepitud (ochenta hasta la muerte). Cf. J. Burgaleta, 48, nota 6. 
tín pecador de estos años existe copiosa bibliografía y disparidad de opiniones, desde quienes interpretan la narración como signo de là gravedad objetiva de los hechos hasta quienes pretenden descubrir en ella una deliberada alteración de los mismos ${ }^{29}$. La crítica actual concuerda en que es preciso distinguir bien entre los hechos narrados y el juicio de rigor de quien los narra: aquéllos pertenecen al pasado y son referidos en su desnuda realidad fáctica $y$ éste, en cambio, al momento en que el autor, escribiendo, contempla dicho pretérito con la óptica nueva de su alta espiritualidad ${ }^{30}$.

Conviene recordar también que entre los motivos que le movieron a escribir las Confesiones - las famosas confessio laudis-confessio peccatorum y el célebre amore amoris tui facio istuc (Conf. II, 1,1) - figura el de aleccionar a sus lectores para evitarles en lo posible los problemas que él hubo de resolver ${ }^{31}$. Más que descender a una simple referencia de pecados, nuestro autor pretende analizar sus causas, el complejo fenómeno de los vicios, la fuerza de las pasiones ${ }^{32}$, la vorágine del mal que separa de Dios ${ }^{33}$. La de esta época precoz no es aún lejanía intelectual. Pero sí moral. De hecho el obispo

29. Cf. P. Alfaric, L'évolution intellectuelle de saint Augustin. I, Du Manichéisme au Néoplatonisme, Paris 1918, 1-61; J.J. O'MEARA, The young Augustine. The grouth of St. Augustine's mind up to conversion, Longman, Green et Coltd, London 1954 (la 3. ${ }^{a}$ ed., con subtítulo cambiado y bibliografía actualizada: Longman, London-New York 1980); A. TRAPE, Introduzione (alle Confessioni): NBA I, Città Nuova, Roma ${ }^{3} 1975$, pp. IX-CXXI; A. PINCHERLE, Vita di sant'Agostino, Bari 1980, 11-16. Más información bibliográfica en F. De CAPITANI: LA/I, 90105; L.F. Pizzolato: LA/I, 44ss.

30. Aquí subyacen los problemas de la historicidad de los Diálogos y las Confesiones y el del Agustín narrante y narrado. Cf. A. Pincherle, The Confessions of St. Augustine: a Reappraisal: AugS 7 (1976) 119-121ss.; C.P. MAYER, Erfahrung und Rechenschaft in Augustins Confessiones: Augustiniana 29 (1979) 140ss.; A Trape, S. Agostino. L'uomo, 45-51; ID., Introduzione: NBA I, p. XCI; F. DE CAPITANI: LA/I, 102.

31. Cf. Retract. II, 32: «Confessionum mearum libri tredecim et de malis et de bonis meis deum laudant iustum et bonum atque in eum excitant humanum intellectum et affectum» (CSEL 36, p. 137); Conf. II, 3,5: «cui narro haec?... et ut quid hoc? ut videlicet ego et quisquis haec legit cogitemus, de quam profundo clamandum sit ad te» (CSEL 33/1, p. 32); X, 3,4: «nam confessiones praeteritorum malorum meorum, quae remisisti et texisti..., cum leguntur et audiuntur, excitant cor, ne dormiat in desperatione et dicat: 'Non possum', sed evigilet in amore misericordiae tuae et dulcedine gratiae tuae, qua potens est omnis infirmus, qui sibi per ipsam fit conscius infirmitatis suae» (p. 228); II, 7,15; XI, 1,1; S. Posidio, VA, prol. Sobre los conceptos confessio

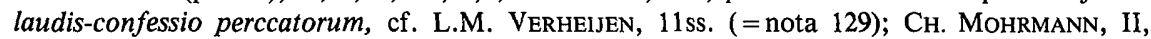
277ss.; I, 30ss. (= nota 129); J. RATZINGER, Originalität und Überlieferung in Augustins Begriff der confessio: REAug 3 (1957) 375-395; A. SolignaC: BAug 13, 9-12; L.F. Pizzolato, Le «Confessioni» di sant'Agostino. Da biografia a 'confessio', Milano 1968, 157-395; ID.: LA/I, 11-33 (bibl.: 11, nota 14). Sobre la posibilidad de celebrar como alabanza incluso la confessio peccatorum, cf. E. DASSMANN, Preisen und Bekennen. Sünde und Gnade in der Erfahrung und Theologie Augustins: Wissenschaft und Weisheit 43 (1980) 4ss.; P. SinisCALCO: LA/III, 96-98:

32. A. Trapè, S. Agostino. L'uomo, 45.

33. Conf. I, 18,28: «in vanitates ita ferebar et a te, deus meus, ibam foras» (p. 25); I, 15,24; 16,25 . 
de Hipona no duda en describirla con la parábola del hijo pródigo que se marcha a lejanas tierras: in longinqua regione vivens prodige dissiparet quod dederas ${ }^{34}$.

\section{A: Puericia}

El niño Agustín entra «en el proceloso mar de la sociedad» ${ }^{35}$ pendiente de la autoridad de sus padres y de las indicaciones de sus mayores ${ }^{36}$. Invoca entonces a Dios como a su refugio y amparo ${ }^{37}$. Los primeros pecados, sin embargo, llegan pronto: negligencia en el estudio ${ }^{38}$, desobediencia por causa del juego ${ }^{39}$, hurtos en la despensa, mentiras; en fin, actos que hoy llamaríamos chiquilladas propias de temprana edad ${ }^{40}$. Hasta equí la referencia desnuda de unos hechos. ¿Qué decir de sus causas? Veamos:

«Pecaba yo, Dios mío, en aquella edad - explica el psicólogo - al anteponer aquellas cosas vanas a estas provechosas, arrastrado únicamente del gusto. O por mejor decir: al amar aquéllas y odiar éstas» ${ }^{41}$. Ya tenemos, pues, un anteponer e implícitamente un posponer; un amar y un odiar; es decir, opciones de una voluntad libre. Y el teólogo ayuda al psicólogo con nuevos matices: «En lo que pecaba yo entonces era en buscar en mí mismo y en las demás criaturas, no en él (Dios), los deleites, grandezas y verdades, por lo que caía luego en dolores, confusiones y errores» ${ }^{42}$. Además de la raíz del pecado

34. Conf. I, 18,28 (pp. 25-26); I, 13,20: «unde et hoc nisi de peccato et vanitate vitae, qua caro eram et spiritus ambulans et non revertens (Ps 77,39)» (p. 18: cf. L.F. Pizzolato: 57, n. 213:... C'è, in transparenza, il tema dell'abbandono della casa paterna da parte del figlio prodigo). Y aún más claro en Conf. I, 18,19 (cf. nota 23).

35. Conf. I, 8,13 (BAC 11/II, 85); I, 16,25: «Sed vae tibi, flumen moris humani! quis resistit tibi? quamdiu non siccaberis? quousque volves Evae filios in mare magnum et formidolosum, quod vix transeunt qui lignum conscenderint?» (p. 22); I, 16,26: «o flumen tartareum» (p. 23); Sab 14,5; S. Ag., In Io. 2,4. Además de la nota 16, cf. H. RoNDET, Le symbolisme de la mer chez saint Augustin: AugM II, 691-701; P. LANGA, La teología náutica en la Catequesis de los Padres: Teología Espiritual 88 (1986) 107-117.

36. Conf. I, 8,13.

37. Conf. I, 9,14 .

38. Conf. I, 9,15 .

39. Conf. I, 10,16: «Peccabam faciendo contra praecepta parentum et magistrorum illorum» (p. 14); I, 9,15: «delectabat ludere» (p. 14); I, 10,16: «amore ludendi» (p. 15); I, 19,30.

40. Conf. I, 19,30: «furta etiam faciebam de cellario parentum et de mensa» (p. 27); I, 19,30: «fallendo innumerabilibus mendaciis et paedagogum et magistros et parentes» (p. 27). Hay que andarse con mucha cautela, pues, y saber interpretar frases como: «siendo niño tan chiquito y tan gran pecador»: tantillus puer et tantus peccator (I, 12,19: BAC 11/II,90; CSEL 33/1, p. 17); o: «me sacaste de mis pésimos caminos» (I, 15,24: BAC 11/II, 94), etc. Cf. A. MANDouze, Saint Augustin, 65; A. Trapè, S. Agostino. L'uomo, 46; J. Burgaleta, 48.

41. Conf. I, 13,22 (BAC 11/II, 93).

42. Conf. I, 20,31 (BAC 11/II, 102); I, 13,21: «No te amaba y fornicaba lejos de ti, y, fornicando, oía de todas partes: ‘¡Bien! ¡Bien!’, porque la amistad de este mundo es adulterio contra ti» (BAC 11/II, 91s.). 
maravillosamente descrita en ese buscar lo que no es Dios y ese buscar fuera de Dios, adviértase la antítesis ternaria de substantivos para describir sus consecuencias. Agradece a Dios sus divinas misericordias, «con las cuales me sacaste de mis pésimos caminos» ${ }^{43}$, y por haberle perdonado ya «los pecados de deleite cometidos en tales vanidades» ${ }^{44}$, pues reconoce haber sido «arrebatado por la vanidad de tales bagatelas» ${ }^{45} \mathrm{y}$ haber muerto un tiempo para Dios por dichas causas ${ }^{46}$.

Son estas observaciones psicológicas y teológicas las que imprimen interés pedagógico fuera de lo común a unas travesuras infantiles de suyo irrelevantes. Lo habremos repetido una y cien veces: que el árbol torcido sólo se puede enderezar cuando es pequeño, y que de no hacerlo entonces el mal se agravará hasta un punto irreversible. Y quien dice el árbol, dice la gotera y la casa amenazando ruina y la enfermedad y el carácter. Estamos ante axiomas con resonancia evangélica. Pues bien, he aquí el texto agustiniano alusivo a la idea: «Porque estas mismas cosas que se hacen con los ayos y maestros por causa de las nueces, pelotas y pajarillos, se hacen cuando se llega a edad mayor con los prefectos y reyes por causa del dinero, de las fincas y siervos, del mismo modo que a las férulas se suceden suplicios mayores» ${ }^{47}$.

Acerca de la enfermedad y del bautismo inminente que luego, ante la mejoría experimentada acabó por diferirse, encontramos otro texto por el que se trasluce ${ }^{48}$ un implícito canto a la eficacia sacramental: «iCuánto mejor me hubiera sido recibir pronto la salud y que mis cuidados y los de los míos se hubieran empleado en poner sobre seguro bajo tu tutela la salud recibida de mi alma, que tú me hubieses dado!» ${ }^{49}$. ¿Se habrían evitado los males posteriores, es decir, aquella otra lejanía, la del orgulloso intelectual, si se le hubiese admi-

43. Conf. I, 15,24 (BAC 11/II, 94).

44. Conf. I, 15,24 (BAC 11/II, 95).

45. Conf. I, 17,27 (BAC 11/II, 98).

46. Conf. $\mathrm{I}, 13,20$ : «cum interea me ipsum in his a te morientem, deus vita mea, siccis oculis ferrem miserrimus» (p. 18); II, 4,9: «sed defectum meum ipsum amavi, turpis anima et dissiliens a firmamento tuo in exterminium» (p. 36). Nótese la antítesis a te morientem, deus vita mea. Cf. Burgaleta, 49, n. 14.

47. Conf. I, 19,30 (BAC 11/II, 101).

48. Conf. I, 11, 17-18 (BAC 11/II, 88-89).

49. Conf. I, 11,18 (BAC 11/II, 89). La reflexión agustiniana no resta fuerza argumental a quienes hoy prefieren administrarlo - si no hay garantías de formación cristiana por parte de padres o padrinos- cuando la criatura sepa qué recibe y a lo que se compromete. El Agustín cuyo bautismo se prefiere diferir no es, precisamente, un bebé. Precisa él mismo que «siendo todavía niño oí ya hablar de la vida eterna» (Conf. I, 11,17: cf. nota 1). Y sobre todo lo siguiente: «Tú viste también, Dios mío yues eras ya mi guarda, con qué fervor de espíritu y con qué fe solicité (=flagitavi) de la piedad de mi madre y de la madre de todos nosotros, tu Iglesia, el bautismo de tu Cristo, mi Dios y Señor» (BAC 11/II, 88). Cf. V. GrossI-A. Di Berardino, La Chiesa antica: ecclesiologia e istituzioni, Roma 1984, espec; 1. L'iniziazione cristiana e i suoi riti (Di Berardino, 55-76). 
nistrado entonces el bautismo? En opinión de quienes prefirieron aplazarlo parece que no ${ }^{50}$. La del Santo, como ahora veremos, es distinta, sin que implique necesariamente responder que sí. Ya es sintomático, de entrada, que se pregunte si fue para su bien «el que se aflojaran, por decirlo así, las riendas del pecar» ${ }^{51}$. Pero es que resulta más revelador que a continuación compare entre la salud del alma y la del cuerpo ${ }^{52}$, y que termine con esta conclusión reiteradamente asertiva, toda ella pura claridad: «iCuánto mejor me hubiera sido recibir pronto la salud...! Mejor fuera, sin duda» ${ }^{53}$.

Deplora también el obispo Agustín haber llorado a esta edad la muerte de Dido y no la propia, causada por falta de amor a Dios, «luz de mi corazón, pan interior de mi alma, virtud fecundante de mi mente y seno amoroso de mi pensamiento» ${ }^{54}$. ¿Hay algo «más miserable - se pregunta- que el que un mísero no tenga misericordia de sí mismo?». La belleza del latín impone citar por el original: Quid enim miserius misero non miserante se ipsum? ${ }^{55}$. Toda falta de amor a Dios constituye una fornicación del alma ${ }^{56}$, y vuelve con este inmarcesible pensamiento teológico: «porque la amistad de este mundo es adulterio contra ti» ${ }^{57}$.

La perniciosa influencia de maestros orgullosos tampoco escapa a su agudo análisis, de tal modo que ni le sorprende el que se dejara arrastrar por las vanidades y se alejara de Dios con modelos tan hinchados de vanidad ${ }^{58}$. Para un tiempo como el nuestro, fuertemente condicionado por los medios de comunicación, y en un caso como el suyo, inquieto joven aficcionado a la lectura, tiene también interés el que afirme que las alabanzas contenidas en las Escrituras deben ejercitar el ingenio y la lengua desde temprana edad, antes que cualesquiera ocupaciones humanas ${ }^{59}$.

50. Conf. I, 11,17: «Difirióse, en vista de ello, mi purificación, juzgando que sería imposible que, si vivía, no me volviese a manchar y que el reato de los delitos cometidos después del bautismo es mucho mayor y más peligroso» (p. 88; cf. la nota 47 del P. Vega en BAC 11/II, 108); I, 11,18: «pero conío mi madre preveía ya cuántas y cuán grandes olas de tentaciones me amenazaban después de la niñez, quiso ofrecerles más bien la tierra, de donde había de ser formado, que no ya la misma imagen» (p. 89; aquí la palabra tierra es sinónima de alma; y la gracia bautismal, la fe, sinónimo de forma del alma: P. VEGA, p. 108, n. 51).

51. .Conf. I, 11,18 (p. 89).

52. $\quad I b . \mathrm{I}, 11,18$ : «¿De dónde nace ahora el que de unos y de otros llegue a nuestros oídos de todas partes: 'Dejadle; que obre; que todavía no está bautizado'; sin embargo, que no digamos de la salud del cuerpo: 'Dejadle; que reciba aún más heridas, que todavía no está sano’?» (p. 89).

53. Ib. I, 11,18 (p. 89)

54. Ib. I, 13,21 (p. 91).

55. Ib. I, 13,21 (p. 91).

56. Ib. I, 13,21 (pp. 91-92).

57. Ib. I, 13,21: «amicitia enim mundi huius fornicatio est abs te» (CSEL 33/1, p. 19; BAC 11/II, 92).

58. Ib. 18,28 (p. 98).

59. Ib. I, 17,27: «Tus alabanzas, Señor, tus alabanzas, contenidas en tus Escrituras, debieran haber suspendido el pámpano de mi corazón, y no hubiera sido arrebatado por la vanidad de 


\section{B: Adolescencia}

Los pecados de esta etapa fueron más graves, es cierto, aunque también aquí hay que matizar mucho ${ }^{60}$. En síntesis, fueron: 1) caídas en materia de castidad; 2) pasión por los espectáculos; 3 ) robo de unas peras en el huerto del vecino; y $4 .^{\circ}$ ) unión que hoy decimos libre (more uxorio) con una joven cartaginesa. Como el último rebasa la cronología del Hortensius, me atendré sólo a los tres primeros. Estamos en el decimosexto año de edad, transcurrido en Tagaste, a la espera de acudir a Cartago, forzosamente interrumpidos los estudios al regreso de Madaura ${ }^{61}$.

Por entonces fue cuando ardió en deseos de hartarse de las cosas más bajas ${ }^{62}$. Estas y otras frases, por ejemplo las del párrafo que voy a citar, pueden inducir a errores de apreciación, si no se interpone oportuna y aclaratoria la distinción entre el Agustín narrante y el Agustín narrado. Advierta el lector la viveza de colorido y la riqueza de imágenes que el Santo emplea para describir lo que hoy denominamos crisis de pubertad: «¿Y qué era lo que me deleitaba, sino amar y ser amado? Pero no guardaba modo en ello, yendo de alma a alma, como señalan los términos luminosos de la amistad, sino que del fango de mi concupiscencia carnal y del manantial de la pubertad se levantaban como unas nieblas que obscurecían y ofuscaban mi corazón hasta no discernir la serenidad de la dilección de la tenebrosidad de la libídine. Uno y otro abrasaban y arrastraban mi flaca edad por lo abrupto de mis apetitos y me sumergían en un mar de torpezas. Tu ira había arreciado sobre mí y yo no lo sabía. Me había hecho sordo con el ruido de la cadena de mi mortalidad, justo castigo de la soberbia de mi alma, y me iba alejando cada vez más de ti, y tú lo consentías; y me agitaba, y derramaba, y esparcía, y hervía con mis fornicaciones y tú callabas, ;oh tardo gozo mío!; tú callabas entonces, y yo me iba cada vez más lejos de ti tras muchísimas semillas estériles de dolores con una soberbia abyección y una inquieta laxitud» ${ }^{63}$. A lo medular de esta interesante cita apuntan otros textos del mismo libro II ${ }^{64}$.

unas bagatelas, víctima de las aves. Porque no es de un solo modo como se sacrifica a los ángeles transgresores». En ese víctima de las aves el P. Vega quiere ver una alusión a las aves del cielo, es decir los demonios, de la parábola del sembrador (p. 98; 110, n. 76).

60. Cf. P. Vega: 11/II, 127, n. 1; A. Trapè, S. Agostino. L'uomo, 47s.

61. Cf. nota 28 .

62. Conf. II, 1,1: «exarsi enim aliquando satiari inferis in adulescentia et silvescere ausus sum variis et umbrosis amoribus, et contabuit species mea et conputrui coram oculis tuis placens mihi et placere cupiens oculis hominum» (CSEL 33/1, p. 29). Cf. nota 98.

63. Conf. II, 2,2, (BAC 11/II, 112-113). Acerca de expresiones como «si et amantis corpore fruerer» (Conf. III, 1,1, p. 45); «...et silvescere ausus sum variis et umbrosis amoribus» (II, 1,1, p. 29), etc., y de la desafortunada y torpe interpretación que de ellas han hecho algunos autores (cf. Papini, Fabre, etc.), cf. las documentadas, oportunas y certeras puntualizaciones de Legewie, Marrou, Courcelle, Trapè; espec. Mandouze, Saint Augustin, 79, nota 5; O. Tescari, (= nota 24); F. De Capitani: LA/I, 102-103.

64. Conf. II, 2,4: «Sed efferbui miser, sequens impetum fluxus mei relicto te, et excessi om- 
Referida la disolución de sus afectos por el juego ${ }^{65}$, introduce el robo de las peras del siguiente modo: «También yo quise cometer un hurto y lo cometí, no forzado por la necesidad, sino por penuria y fastidio de justicia y abundancia de iniquidad, pues robé aquello que tenía en abundancia y mucho mejor. Ni era el gozar de aquello lo que yo apetecía en el hurto, sino el mismo hurto y pecado" ${ }^{66}$. Sobre el mencionado robo gira el resto del libro II ${ }^{67}$.

Pero lo que nuevamente importa no es tanto la referencia del pecado en sí cuanto el análisis psicológico y teológico que del relato se desprende. Empecemos subrayando el egoísmo - placens mihi et placere cupiens oculis hominum -, verdadera causa de que se marchitara su hermosura y se volviera podredumbre a los ojos de Dios ${ }^{68}$, de que se oscureciera y ofuscara su corazón -obnubilabant atque offuscabant cor meum - por la pendiente de la concupiscentia carnis ${ }^{69}$ hasta naufragar en un mar de torpezas: mersabat gurgite flagitiorum ${ }^{70}$. Continuemos destacando su impermeabilidad a los buenos consejos, pues él mismo puntualiza que las amorosas reconvenciones de su madre, voces de Dios al fin y al cabo, le parecían mujeriles (muliebres videbantur) ${ }^{71}$ y le resbalaban de tal modo que «ninguna de ellas penetró en mi corazón para ponerlas por obra» ${ }^{72}$. Y prosigue con esta interesante aclaración: «Me pisoteaba el enemigo invisible y me seducía, por ser yo fácil de seducir» ${ }^{73}$.

He aquí, sobrentendida, la fuerza terrible del mal, la extraña paradoja de su misterio: mientras desoye las advertencias de la madre, el inconsecuente Agustín no siente ningún rubor en secundar el mal ejemplo de sus compañeros recorriendo con ellos «las plazas de Babilonia» ${ }^{74}$, precipitándose «con tanta

nia legitima tua nec evasi flagella tua» (p. 31); II, 3,6: «excesserunt caput meum vepres libidinum, et nulla erat eradicans manus» (p. 33); II, 1,1: «Recordari volo transactas foeditates meas et carnales corruptiones animae meae» (p. 29); II, 3, 7-8.

65. Conf. II, 3,8: «Relaxabantur etiam mihi ad ludendum habenae ultra temperamentum severitatis in dissolutionem affectionum variarum, et in omnibus erat caligo intercludens mihi, deus meus, serenitatem veritatis tuae, et prodiebat tamquam ex adipe iniquitas mea (Ps 72,7)» (p. 35 ).

66. Conf. II, 4,9 (BAC $11 / \mathrm{II}, 118)$.

67. Conf. II, 4, 99-10,18.

68. Conf. II, 1,1 (p. 29): cf. nota 62.

69. Conf. II, 2,2 (p. 30). Sobre concupiscentia carnis en San Agustín, cf. F.-J. THONNARD, La notion de concupiscencé en philisophie augustinienne: RAug 3 (Paris 1965) 59-105; ID., Nature humaine et concupiscence: BAug 23 (Paris 1974) 702-708; P. LANGA, San Agustín y el progreso de la teología matrimonial, Toledo 1984, espec.: III. La concupiscencia, según San Agustín, 259266.

70. Conf. II, 2,2 (p. 30). Cf. nota 62 y 98.

71. Conf. II, 3,7 (p. 34).

72. Conf. II, 3,7 (BAC 11/II, 116).

73. Conf. II, 3,8 (p. 117).

74. Conf. II, 3,8 (p. 117): cf. De civ. Dei, XVIII, 11,1; In ps. 136, 4-5. El obispo de Hipona 
220

P. L NG

12

q

g o-

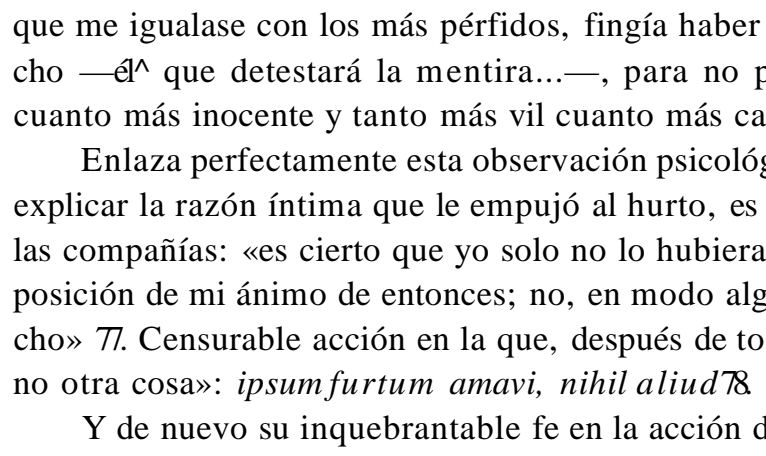

. A

e

?». s

75. ¿Q

$\mathrm{u}$

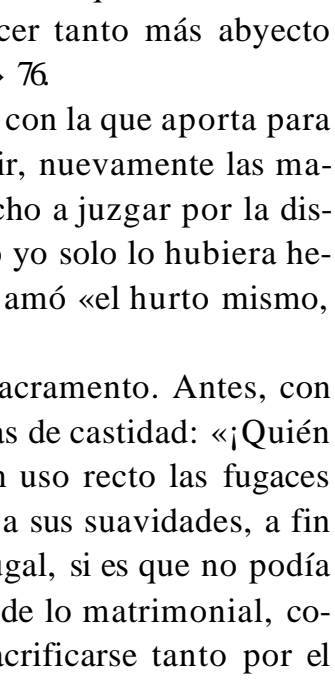

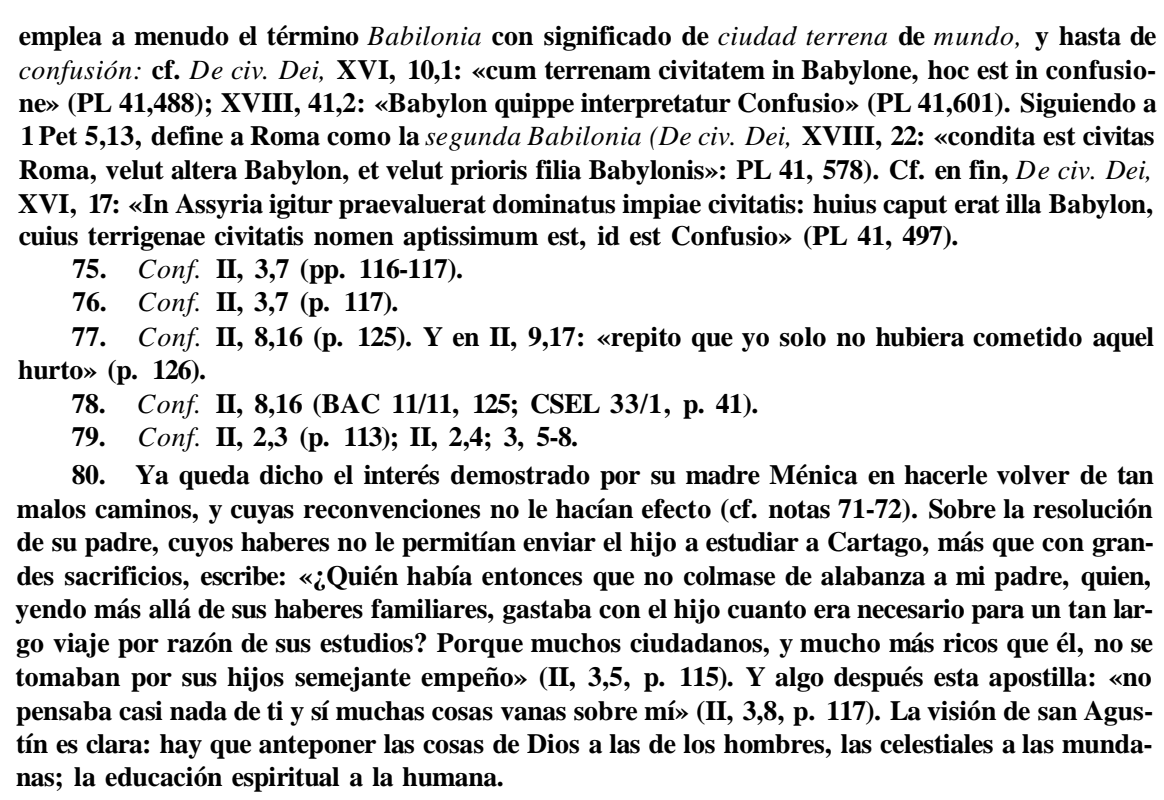


hijo ${ }^{80}$, se cuidaron de resolverle este problema ${ }^{81}$. En cuanto a su madre ${ }^{82}$, cree que fue «porque tenía miedo de que con el vínculo matrimonial se frustrase la esperanza que sobre mí tenía; no la esperanza de la vida futura, que mi madre tenía puesta en ti, sino la esperanza de las letras, que ambos a dos, padre y madre, deseaban ardientemente ${ }^{83}$ Se parece mucho este proceder al de tantos padres de hoy día, cristianos ellos, cómo no, para quienes lo único importante es la carrera civil del hijo, y para nada, en cambio, o bien poco, la formación religiosa. Tratándose de santa Mónica, y acostumbrados como estamos a ver en ella a la santa sacrificada por la conversión del hijo, hay que reconocer que la puntualización precedente le hace poco favor, si bien es cierto que la apostilla que sigue atenúa esa primera impresión negativa, «porque consideraba - dice- que aquellos acostumbrados estudios de la ciencia no sólo no me habían de ser estorbo, sino de no poca ayuda para alcanzarte a ti»» ${ }^{84}$.

Duélese también el Doctor de la Trinidad de no haber atendido a la voz de Dios, siendo así que «no está lejos de nosotros tu omnipotencia, aun cuando nosotros estemos lejos de ti» ${ }^{85}$. Y lo hace volviendo a la carga con lo del

81. Ib. II, 2,4: «Ni aun los míos se cuidaron de recogerme en el matrimonio (=excipere me matrimonio) al verme caer en ella; su cuidado fue sólo de que aprendiera a componer discursos magníficos y a persuadir con la palabra» (p. 114). Este párrafo agustiniano es de una actualidad indudable: sobre todo en una sociedad que ha cuidado tanto de que se aprendan bien las matemáticas, aunque sea a costa de no tener siquiera clase de religión.

82. Ib. II, 3,8: «Ni aun mi madre carnal, que había comenzado a huir ya de en medio de Babilonia (cf. nota 74), pero que en lo demás iba despacio, cuidó - como antes lo había hecho aconsejándome la pureza- de contener con los lazos del matrimonio aquello que había oído a su marido de mí - y que ya veía me era pestilencial y en adelante me había de ser más peligroso-, si es que no se podía cortar por lo sano» (BAC 11/II, 117).

83. Ib. II, 3,8 (BAC 11/II, 117).

84. Ib. II, 3,8 (BAC 11/II, 117). No sería justo aplicar a Santa Mónica un juicio negativo en este comportamiento. Ella y su marido querían, como suele suceder con los padres, lo mejor para el hijo. Aparte las reconvenciones constantes para que fuera casto, está el dato que aporta san Agustín en el sentido de que «había comenzado a huir ya de en medio de Babilonia, pero que en lo demás iba despacio», y en otro lugar: que Dios había empezado a hacer de ella su santuario, que viene a significar una perfección incoada, pero aún no consumada. Es significativo que la Santa viera en los estudios una ayuda para alcanzar a Dios. ¿Qué idea tenía santa Mónica del matrimonio, dada su experiencia personal con Patricio, un pagano al que había tenido que tolerar infidelidades? ¿Temía ella que, de casarse entonces el hijo tal y como estaba, podía empeorar su situación y por eso no pasó por su mente entonces el matrimonio? No es fácil responder a estos interrogantes. Hay que limitarse a la referencia del hijo y pensar, eso sí, que está hecha cuando él es ya obispo y sabe medir los hechos a la luz de una extraordinaria espiritualidad y una firme teología de los sacramentos. Como en el caso del bautismo, san Agustín insinúa que las cosas hubieran . discurrido de otra forma con la ayuda del sacramento. Eso es todo. Cf. las notas del P. Vega en BAC 11/II, 127-130; A. Mandouze, Saint Augustin, 85, 177s.; A. TrapE, S. Agostino. Mia madre, 19ss., 64ss.; L.F. PIzzolato: LA/I, 53s.; P. LANGA, San Agustín y el progreso de la teología matrimonial, 132ss.

85. Conf. II, 2,3 (p. 113). 
mortal abandono de Dios: «Me había hecho sordo con el ruido de la cadena de mi mortalidad, justo castigo de la soberbia de mi alma, y me iba alejando cada vez más de tì ${ }^{86}$. Lejanía y dispersión insinuadas de nuevo por la parábola del hijo pródigo, lo mismo a través de ese «mas yo, miserable, pospuesto tú, me convertí en un hervidero, siguiendo el ímpetu de mi pasión»: sequens impetum fluxus mei relicto te ${ }^{87}$, alusivo al momento de la partida de la casa paterna, que mediante el texto de unas líneas más abajo, sugeridor ya de la miserable situación del hijo en el destierro: «Pero ¿dónde estaba yo? ¡Oh, y qué lejos, desterrado de las delicias de tu casa en aquel año decimosexto de mi edad carnal, cuando empuñó su cetro sobre mí, y yo me rendí totalmente a ella, la furia de la libídine, permitida por la desvergüenza humana, pero ilícita según tus leyes!» ${ }^{88}$. Momento de abandonar la casa paterna, en el primero; estado miserable después de la partida, en el segundo. $\mathrm{Y}$ en ambos, tremenda lejanía de Dios.

Las criaturas todas del mundo -el oro, la plata, el honor, el poder, etc. - tienen su encanto. Bella en extremo es la vida, y deseable sobremanera «la amistad de los hombres por la unión de muchas almas con el dulce nudo del amor» ${ }^{89}$. Mas «para conseguir todas estas cosas no es necesario abandonarte a ti, ni desviarse un ápice de tu ley» ${ }^{90}$, precisa el Obispo de Hipona en diálogo con Dios, y añade más adelante: «Por todas estas cosas y otras semejantes se peca cuando por una inclinación inmoderada a ellas - no obstante que sean bienes ínfimos - son abandonados los mejores y sumos, como eres tú, Señor Dios nuestro; tu Verdad y tu Ley» ${ }^{91}$. Inclinación inmoderada, pues, que provoca el abandono de lo mejor: claramente insinuado el principio de la aversión a Dios y de la conversión a las criaturas. Se produce así el pecado, la separación de Dios, la «fornicación del alma» ${ }^{92}$.

La conclusión del libro II de las Confesiones constituye un prodigio de síntesis expresiva: lo inicia un suspiro de amor a Dios ( $\mathrm{Te}$ volo) que denota de forma tácita el dolorido recuerdo de aquella marcha in longinqua, regionem, como si quisiera de pronto contrarrestar la pasada aversión con este enfervorizado Te volo, en el que se acusan resonancias del «túusabes que te quiero», de

86. Conf. II, 2,2 (p. 113). Repite la idea al final del texto: «y yo me iba cada vez más lejos de ti tras muchísimas semillas estériles de dolores con una soberbia abyección y una inquieta laxitud» (p. 113).

87. Conf. II, 2,4 (BAC 11/II, 114; CSEL 33/1, p. 31).

88. Conf. II, 2,4 (p. 114). Cf. Lc 15, 14-18.

89. Conf. II, 5,10 (p. 119).

90. Ib., p. 119.

91. Ib., p. 120 .

92. Conf. II, 6,14: «Ita fornicatur anima, cum avertitur abs te et quaerit extra te ea quae pura et liquida non invenit, nisi cum redit ad te» (CSEL 33/1, p. 40; BAC 11/II, 123). Cf. nota 177 . 
san Pedro (Jn 21, 15-19). Es, después de todo, sublime idea prolongada mediante yuxtaposición intesiva de vocablos: iustitia et innocentia, pulchra et decora honestis luminibus et insatiabili sacietate ${ }^{93}$. También se incorpora al cuadro el argumento de la quietud divina, el único descanso radical de la inquietud humana, cumbre tabórica del «Nos hiciste, Señor, para ti» (Conf. I, $1,1)^{94}$. Recuerda que Dios es fuente de estabilidad ${ }^{95}$, y que un día él mismo acabó convirtiéndose en regio egestatis ${ }^{96}$ después de vagabundear fuera del camino estable ${ }^{97}$.

\section{C: $E l$ «Hortensius»}

El apuesto Agustín de diecisiete años llega en estas circunstancias a Cartago, tierra de cultivo para su ardorosa sensualidad ${ }^{98}$. Llagado de alma ${ }^{99} \mathrm{y}$ agravadas las caídas ${ }^{100}$, no tarda en ser presa de los espectáculos teatrales ${ }^{101}$. En cambio, rehúye las calaveradas de los eversores ${ }^{102}$, dato hasta cierto punto

93. Adviértase la fuerza de insatiabili satietate (II, 10,18, p. 43), sintagma en el que subyace el dinamismo típico de la teología agustiniana, siempre pendiente de la búsqueda a Alguien a quien es preciso seguir buscando de puro haberlo encontrado. Cf. la teología agustiniana como búsqueda de la Verdad, en: P. LANGA, San Agustín, Teólogo, Toledo 1985, 24-26.

94. Conf. I, 1,1: «quia fecisti nos ad te et inquietum est cor nostrum, donec requiescat in te» (p. 1); II, 10,18: «quies est apud te valde et vita imperturbabilis» (p. 43). A. PINCHERLE, Et inquietum est cor nostrum: Augustinus 13 (1968) 353-368; R. Flórez, Presencia de la verdad, $105-$ 115; G. CERIOTTI, Excursus: Inquietum cor (Confessioni I, 1,1): LA/I, Palermo 1984, 79-88. Para ulteriores matices y bibliografía del tema, cf. L.F. Pizzolato: LA/I, 13ss.

95. Conf. II, 10,18: «qui intrat in te (=en quien reside la «vita imperturbabilis»: cf. nota anterior), intrat in gaudium domini sui (Mt 25,21) et non timebit et habebit se optime in optimo» (p. 43).

96. Conf. II, 10,18: «regio agestatis» (p. 43). Cf. nota 23.

97. Conf. II, 10,18: «defluxi abs te ego et erravi, deus meus, nimis devius ab stabilitate tua» (p. 43). Compárese, stabilitate tua con vita imperturbabilis (cf. nota 94).

98. Conf. III, 1,1: «Veni Karthaginem et circumstrepebat me undique sartago flagitiosorum amorum, nondum amabam et amare amabam et secretiore indigentia oderam me minus indigentem» (p. 43). Nótese el contraste Karthago-sartago, y el reiterativo indigentia-indigentem, y en III, 1,1: «amare et amari dulce mihi erat magis, si et amantis corpore fruerer» (p. 44; cf. notas 70 y 62). Sobre Karthago Veneris (=Ciudad del Placer), cf. S. Ag., De civ. Dei, II, 4 y 15; SALviA. No, De gubernatione Dei, VII, 16; P. VEGA: BAC 11/II, 153, notas 1-2; L. BERTRAND, Saint Augustin, Paris 1913: Carthagè Veneris, 91-98; P. Brown, Agustín de Hipona, 81-91; G. Charles-PiCARd, La Carthage de saint Augustin, Paris 1965, Cf. nota 27.

99. Conf. III, 1,1: «et ideo non bene valebat anima mea et ulcerosa proiciebat se foras» (p. 44).

100. Conf. III, 1,1: «Venam igitur amicitiae coinquinabam sordibus concupiscentiae candoremque eius obnubilabam de tartaro libidinis... rui etiam in amore, quo cupiebam capi» (p. 44); III, 1, 1-4,7. Cf. A. Trapè, S. Agostino. L'uomo, 47. Véanse las notas 62, 70, 98; y la 16.

101. Conf. III, 2,2: «Rapiebant me spectacula theatrica plena imaginibus miseriarum mearum et fomitibus ignis mei» (p. 44). Cf. A. MANDouze, Saint Augustin, 80; Lepelley, II, 40-47; A.-G. Hamman, La vie quotidienne en Afrique du Nord au temps de saint Augustin, Hachette, $1979,146-169$.

102. Conf. III, 3,6: «domine, tu scis, et remotus omnino ab eversionibus quas faciebant eversores - hoc enim nomen scaevum et diabolicum velut insigne urbanitatis est- inter quos vi- 
sorprendente, por cierto ${ }^{103}$. Con la inteligencia diamantina de la que estaba adornado, no es extraño que todo ello contribuyera a un estado de petulancia y soberbia en los estudios ${ }^{104}$.

Tal vez el mejor diagnóstico de la recrudecida situación lo constituya este corto y penetrante juicio: "Así era mi vida. Pero ¿era vida ésta, Dios mío?» ${ }^{105}$. Es curioso que aquello que más ha contribuido a crearle entre la gente sencilla esa imagen de gran pecador, a saber: la unión libre con una joven, la célebre mujer anónima de las Confesiones, arranque de su pluma frases que no se corresponden ni de lejos con la culpabilidad que algunos le imputan. Lo analizará más adelante, fuera ya de los límites impuestos a este trabajo ${ }^{106}$, y de un modo no siempre bien entendido entre la crítica, pero que afortunadamente va encontrando poco a poco entre los estudiosos su adecuado enfoque ${ }^{107}$. Aquí no hace más que aludirlo: «y me dejé atar alegre con ligaduras trabajosas» ${ }^{108}$.

De momento a lo que viene una y otra vez es a la situación autosuficiente y licenciosa, en la que cada día se iba hundiendo más y más. La subida mística de quien escribe acerca de sus pasados devaneos juveniles arrima a la pluma el material evangélico de la contumacia farisaica: «¡Tanta es la ceguera de los hombres, que hasta de su misma ceguera se glorían!» ${ }^{109}$. Y el del atolondrado

vebam pudore inpudenti, quia talis non eram: et cum eis eram et amicitiis eorum delectabar aliquando, a quorum semper factis abhorrebam, hoc est ab eversionibus, quibus proterve insectabantur ignotorum verecundia, quam proturbarent gratis inludendo atque inde pascendo malivolas laetitias suas» (p. 48). Sobre la condición de esta «caterva de estudiantes calaveras», cf. S. Posidio, VA, 30,1: Las interesantes notas del P. VEGA, en BAC 11/II, 154-155; A. Trapè, S. Agostino. L'uomo, 41; A. MANdouZE, Saint Augustin, 81; LEPELley, I, 298-318, II; 45.

103. Sobre todo porque él mismo reconoce que era «fácil de seducir» (Conf. II, 3,8): Cf. notas 73-77. Cf. las interesantes observaciones de Trapè (40-41), quien reconoce que «un altro aspetto dell'indole naturalmente buona di Agostino è la sua profonda avversione per i subbugli degli eversores» (cf. S. Agostino. L'uomo, 41).

104. Conf. III, 3,5: «in quibus vagatus sum praefidenti collo ad longe recedendum a te» (p. 47); III, 3,6: «et maior iam eram in schola rhetoris et gaudebam superbe et tumebam tyfo» (p. 47). Con este orgulloso talante le va a sorprender el Hortensius: «Inter hos ego imbecilla tunc aetate discebam libros eloquentiae, in qua eminere cupiebam fine damnabili et ventoso per gaudia vanitatis humanae, et usitato iam discendi ordine perveneram in librum cuiusdam Ciceronis...» (III, 3,6, p. 48).

105. Conf. III, 2,5 (BAC 11/II, 135).

106. Conf. IV, 2,2; VI, 15,25; IX, 6,14.

107. Cf. P. VEGA: BAC 11/II, 187, nota 12; 266, nota 57; A. SolignAC: BAug 13, 677-679; A. Mandouze, Saint Augustin, 178-179; P. Brown, 77; A. Trape, S. Agostino. L'uomo, 49-51; N. BlÁzQuEZ, San Agustín y el experimentalismo sexual: Arbor 89 (19ł4) 315-326; ID., Feminismo agustiniano: Augustinus 27 (1982) 3-5; 29-33; P. LANGA, San Agustín y el progreso de la teología matrimonial, 132-135 (con bibl. sobre concubinato: 135, n. 213); José M. RodRigueZ, El libro VI de las Confesiones, LA/III, Palermo 1985, 9ss.

108. Conf. III, 1,1: «et perveni ad vinculum fruendi et conligabar laetus aerumnosis nexibus» (CSEL 33/1, p. 44; BAC 11/II, 132).

109. Conf. III, 3,6 (p. 135). 

Señor, mis súplicas e hizo que mis votos y deseos fueran otros. De repente apareció a mis ojos vil toda esperanza vana, y con increíble ardor de mi corazón suspiraba por la inmortalidad de la sabiduría, y comencé a levantarme para volver a ti» ${ }^{120}$.

Profunda fue la impresión - no era el estilo lo que en la lectura buscaba, sino lo que decía - ${ }^{121}$ y profundo de igual modo el cambio producido, pues transformó afectos, mudó súplicas, rectifico votos y deseos. La referida conversión interior se percibe también por la nueva actitud del universitario ante las cosas: de repente - elemento sorpresa propio de las conversiones radicales - le pareció vil toda esperanza vana - es decir, vieja y repudiable-, de tal modo que empezó a suspirar por la inmortalidad de la sabiduría —o por la casa paterna, recurriendo una vez más al hijo pródigo - y a levantarse para volver a Dios: et surgere coeperam, $u$ t ad te redirem ${ }^{122}$ : de la noche hacia el día, de lejanas tierras hacia la casa del padre, de la regio dissimilitudinis a la vita imperturbabilis. Era la luz. Y el límite impuesto a estas páginas.

\section{PEDAgogía AgUSTINIANA DE ESTA PRIMERA AVENTURA}

¿Qué valor pedagógico puede tener, sobre todo para la juventud que celebra el XVI Centenario de la Conversión de san Agustín, el recuerdo de una aventura fundamentalmente dispersiva? ${ }^{123}$. ¿No sería preferible omitir la primera fase, de aversión a Dios al fin y al cabo, para salir directamente al camino del retorno? ${ }^{124}$. Al final de Conf. II encontramos un pensamiento agustiniano que parece apoyar la estrategia ${ }^{125}$. Ocurre, sin embargo, que debe entenderse a la luz del más amplio y plausible propósito del autor de las Confesiones, sobrentendido en los sintagmas confessio laudis-confessio peccatorum $^{126}$. La suprema aspiración pedagógica del autor en esta celebrada obra

120. Conf. III, 4,7 (p. 137).

121. Ib. III, 4,7 (p. 137).

122. Ib. III, 4,7 (CSEL 33/1, p. 48; BAC 11/II, 137). Cf. Lc 15,19.

123. Aunque de alguna manera quede interrumpida por esta «primera conversión» experimentada con la lectura del Hortensius, porque a esta aversión moral vendrá a sumarse pronto la intelectual del maniqueísmo (cf. nota 4). Y con independencia todo ello, desde luego, de las vicisitudes mencionadas en las nota 8-10 y lo que ellas representan en la fase general de aversión a Dios, de lejanía, que se da en el proceso total de la conversión agustiniana.

124. En más de un noviciado, y en épocas no tan lejanas, llegó a prohibirse la lectura de las Confesiones, a causa precisamente de lo narrado en estos libros primeros. Algo similar a lo acontencido con el Cantar de los Cantares. Como se ve, el espíritu alicorto y cicatero da a veces la sensación de no tener límites.

125. Conf. II, 10,18: «Quis exaperit istam tortuosissimam et implicatissimam nodositatem? foeda est; nolo in eam intendere, nolo eam videre» (p. 43).

126. Además de la nota $31, \mathrm{cf}$. P. SinISCALCO, Le tappe di un itinerario interiore ed esterno del IX libro delle 'Confessiones' di Agostino: LA/III, 89-110:90-93. 
fue la de excitar los corazones hacia el bien, incluso desde el recuerdo de sus caídas, de suerte que en sus lectores - nosotros hoy- se produzca también una Confessio laudis y una confessio peccatorum ${ }^{127}$.

Finalidad esta cumplidamente alcanzada, en mi opinión, gracias al lúcido y precioso análisis retrospectivo que el fervoroso Agustín de Hipona hace de la primera aventura protagonizada por el mundano Agustín, en diálogo permanente con Dios desde el diálogo consigo mismo: Augustinus ipse cum Augustino ${ }^{128}$. Muchas son las perspectivas que permiten demostrarlo. Insistiré sólo en tres: $1 .^{a}$ ) El Agustín estilista; $2 .^{a}$ ) el Agustín psicólogo; y 3..$^{a}$ ) el Agustín teólogo.

\section{1. a) Agustín, estilista}

Sobre todo, y especialmente para nuestro caso, por lo que atañe al dominio de la metáfora ${ }^{129}$. La que aquí utiliza es una metáfora pletórica de colorido y de belleza, con matriz unas veces neoplatónica ${ }^{130}$ y más a menudo bíblica ${ }^{131}$, con imágenes multicolores y llenas de alma ${ }^{132}$, occidental y medi-

127. Cf. notas 31, y 126 .

128. Ep. 3,1 (CSEL 34/1, p. 5,11).

129. Cf. C.-I. BALmus, Étude sur le style de saint Augustin dans les Confessions et la Cité de Dieu, Paris 1930; M. VerheIJen, Eloquentia Pedisequa. Observations sur le style des Confessions de saint Augustin, Nijmegen 1949, aunque omite el tema de la metáfora, excepto la metáfora del «genitivo de definición», 135-136; J. Fontaine, Sens et valeur des images dans les Confessions: AugM I, 117-126; L.F. Pizzolato, Le fondazioni dello stile delle "Confessioni» di sant'Agostino, Milano 1972. Muy útiles los tomos de Ch. Mohrman, Études sur le latin des chrétiens, Roma 1961-1977, espec.: Saint Augustin and the «Eloquentia» (I, 351-370), The Confessions as a litterary work of art (I, 371-381); Comment Saint Augustin s'est familiarisé avec le latin des chrétiens (I, 383-389); Saint Augustin écrivain (II, 247-275); Considerazioni sulle «Confessioni») di sant'Agostino (II, 277-323). Cf. más bibl. en V. CAPÁNAGA: BAC 10/I, 739; y en A. TRAPE, BAC 422, p. 496.

130. Cf. Conf. VII, 10,16: «regio dissimilitudinis» (p. 157); I, 18,28: «nam longe a vultu tuo in affectu tenebroso» (p. 25); 1, 18,29: «lege infatigabili spargens poenales caecitates supra inlicitas cupiditates» (p. 26); II, 2,2; II, 3,7. etc. Courcelle llama a estas y otras expresiones «l'imagerie néoplatonicienne»: cf. Les Confessions de Saint Augustin dans la tradition littéraire. Antécédents et Postérité, Paris 1963, 278-79, 297; ID., La colle et le clou de l'âme dans la traditions néoplatonicienne et chrétienne: Revue belge de philologie et d'histoire 36 (1958) 72-95: 80-84; J. FonTAINE, 119.

131. Cf. Conf. II, 10,18: «regio egestatis» (p. 43); I, 18,28: «in longinqua regione» (p. 24). Sobre las parábolas del hijo pródigo y de la oveja perdida, cf. notas 23 y 115 ; y sobre Babilonia, cf. nota 74. Aunque algunas amágenes puedan arraigar en el neoplatonismo, la mayor parte responden a la Biblia según demuestran M. VerheiJen, 143; J. FonTAINE, 119; A. MANDouze, Saint Augustin, 75; Ch. MohrmanN, II, 260ss.; 318-321.

132. Cf. J. FinAerT, L'évolution littéraire de saint Augustin, Paris 1939, 113-122: 116; J. Fontaine, 117ss.; Ch. Mohrmann, I, 374ss.; II, 261-265; A. MANdouze, Saint Augustin, 75. 
terránea ${ }^{133}$, al servicio siempre de un fin religioso ${ }^{134}$. El depurado estilista de las Confesiones llega con elegancia y precisión al lector, sabe trabajar los vocablos como un orfebre del idioma, recurre a imágenes y símbolos de la vida infantil, de la juventud y de la madurez ${ }^{135}$, y a estampas sobrecogedoras de la tierra ${ }^{136}$ y del mar ${ }^{137}$, de la cárcel y el fuego ${ }^{138}$; recorre caminos tortuosos y abruptos ${ }^{139}$ igual que pinta embravecidos mares, playas tranquilas y nieblas espesas ${ }^{140}$.

Los vocablos acuden dóciles a su pluma para expresar con lirismo la torpeza de las pasiones, para engalanar la idea; abunda en ellos el movimiento peligroso y el dinamismo de regresión — no se olvide que está confesando una aventura constituida por acciones fundamentalmente dispersivas- como si con ello pretendiera poner de manifiesto que, una vez dadas las espaldas a la divinidad, ese peregrinar que antes era gratificante y alegre porque llevaba hacia Dios se convierte de pronto en triste y fatigoso porque conduce a la encar-

133. En la que abundan la luz, la tierra, el fuego, el sol con los matices que estos elementos revisten en las áreas del Mediterráneo; no son, por ejemplo, las que el lector encuentra en los famosos Carmina Nisibena, de San Efrén, que reflejan un cristianismo aramaico y mesopotámico: cf. F. RILLIET, Efrén Siro: DPAC I (Marietti 1983) 1103-1107:1106. No es tampoco la metáfora oriental, de la que informa estupendamente P. Evdokímov en: La teologia della belleza, Roma 1971.

134. Ch. MOHRMANN, II, 279ss.

135. Cf., por ejemplo, el uso del diminutivo: nueces, pelotitas, pajarillos (I, 19,30); el niño que aprende a hablar (I, 8,13); el robo de las peras (II, 4, 9-10,18); la arrogancia del adolescente y del joven frente a un mundo circundante y dentro de un ambiente disoluto (III, 1, 1-4,7).

136. Cf. Conf. II, 3,5: «...dummodo essem disertus vel desertus potius a cultura tua, deus, qui es unus verus et bonus dominus agri tui, cordis mei» (p. 33); II, 2,2: «per abrupta cupiditatum» (p. 30); II, 3,6: «vepres libidinum» (p. 33); II, 2,2: «scatebra pubertatis» (p. 30); II, 2,2: «sterilia semina dolorum» (p. 30); I, 16,26: «flumen tartareum» (p. 23); II, 2,2: «limosa concupiscentia carnis» (p. 30); II, 10,18: «regio egestatis»: IX, 10,24: «regio ubertatis».

137. Conf. I, 8,13: «procellosam societatem» (p. 12); II, 2,4: «vesania libidinis» (p. 31); II, 2,2: «gurgite flagitiorum» (p. 30); II, 2,3: «et usque ad coniugale litus aestuarent fluctus aetatis meae» (p. 30); I, 19,30: «in limine iacebam miser, et huius harenae palestra erat illa» (p. 27); III, 1,1: «et circumstrepebat me undique sartago flagitiosorum amorum» (p. 43).

138. Conf. II, 1,1: «exarsi enim aliquando satiari» (p. 29); II, 2,2: «et ebulliebam per fornicationes meas» (p. 30); III, 2,2: «fomitibus ignis mei» (p. 44); II, 2,2: «obsurdueram stridore catenae mortalitatis meae» (p. 30; imagen claramente platónica: cf. J. FonTAINE, 119, nota 4).

139. Conf. II, 2,2: «per abrupta cupiditatum» (p. 30); I, 15,24: «eruisti me ab omnibus viis meis pessimis» (p. 21); II, 4,9: «ecce cor meum, quod miseratus es in imo abyssi» (p. 36).

140. Conf. II, 2,2: «sed exhalabantur nebulae... et obnubilabant atque obfuscabant cor meum, ut nọn discerneretur serenitas dilectionis a caligine libidinis» (p. 30); II, 2,3: «ad coniugale litus aestuarent fluctus aetatis meae» (p. 30); III, 1,1: «tartaro libidinis» (p. 44). Cf. notas 16, 35 y 137. 
celación, es decir, a una libertad maniatada ${ }^{141}$. Los vocablos de la salud y de la enfermedad escalan alturas espirituales ${ }^{142}$.

Bastaría la descripción de la crisis de pubertad ${ }^{143}$, o de cómo le entró Cartago por los ojos ${ }^{144}$, incluso las finas pinceladas sobre el niño que aprende a leer ${ }^{145}$, para quedar inmortalizado entre los grandes nombres de la república literaria. Es verdad que los tiempos actuales están más por el fondo que por la forma, que las prisas exigen decir las cosas con rapidez más que con brillantez, pero curiosamente en pocas épocas de la historia ha funcionado tanto la manipulación del lenguaje como ahora, lo que significa el empleo forzoso de una técnica lingüística determinada.

En cualquier tarea pedagógica, se quiera o no, importa mucho saber decir las cosas. La aceptación o el rechazo de un mensaje, de una doctrina, de un argumento, depende de cómo se transmita de palabra o por escrito. El Obispo de Hipona pretendía por todos los medios llegar al público, y como ahora se dice: impactar. Y ello, desde luego, por encima de normas y reglas gramaticales, pues le importaba más ser entendido de los fieles que censurado de los gramáticos ${ }^{146}$. Pero este romper con un estilo no era otra cosa, en el fondo, que exigencias de guión, e imperativos de otro estilo: el suyo. En este caso de las Confesiones, obra espléndida, de incomparable lirismo y vibración cordial, el de su elegante y bien cortada pluma, puesta al servicio de una aventura

141. Conf. II, 10,18: «quies est apud te valde et vita imperturbabilis» (p. 43: cf. I, 1,1: «...et inquietum est cor nostrum, donec requiescat in te», p. 1); II, 2,2: «et ibam longius a te, ...et ego ibam porro longe a te» (p. 30); II, 2,2: «obnubilabant atque obfuscabant» (p. 30); II, 3,8: «et seducebat me, quia ego seductilis eram» (pp. 34-35); III, 1,1: «et conligabar laetus aerumnosis nexibus» (p. 44); III, 2,2: «Rapiebant me spectacula theatrica» (p. 44).

142. Conf. III, 1,1: «sordibus concupiscentiae» (p. 44); II, 6,14: «O putredo» (p. 40); III, 2,2,: «plena imaginibus miseriarum mearum» (p. 44); II, 2,3: «aerumnam meam» (p, 30); II, 2,2: «limosa concupiscentiae carnis» (p. 30); III, 1,1: «et ideo non bene valebat anima mea et ulcerosa proiciebat se foras» (p. 44); III, 2,4: «infelix pecus aberrans a grege tuo et impatiens custodiae tuae turpi scabie foedarer» (p. 46).

143. Conf. II, 2,2 (CSEL 33/1, pp. 29-30; BAC 11/II, 112-113).

144. Conf. III, 2,2 (CSEL 33/1, pp. 44-46; BAC 11/II, 132-133). «Il faudrait pouvoir citer tout le passage: je connais en tout cas peu de textes où le plaisir ambigu du théâtre soit plus finement analysé (on serait presque tenté de dire psychanalysé). A tout le moins, cette «confession littéraire» nous donne d'Augustin à Carthage une image qui laisse présager pour lui une autre carrière que celle de voleur de poires ou de trousseur de filles» (A. MANDOUZE, Saint Augustin, 80).

145. Conf. I, 8,13 (CSEL 33/1, pp. 11-12; BAC 11/II, 84-85). Ch. Mohrmann asegura que «Sous la forme très simple d'un récit, Augustin nous donne ici, dans une langue claire et suggestive, sans artifices, une analyse de la manière dont l'enfant fait l'apprentissage de la langue», después de anticipar que en las exposiciones de orden filosófico o psicológico «son style est d'une clarté extrême, simple, parfois même dépouillé» (II, 260).

146. Cf. In ps. 138,19; In ps. 36,s. 3,6; 37,14. Buenas reflexiones al respecto en Mohrmann, II, 247-275; 322-323; H.-I. MARRou, Saint Augustin et la fin de la culture antique, espec. la tercera parte sobre doctrina christiana: 329-540; P. BROWN, 343-357; y concretamente A. TRAPË: BAC 422, pp. 416-418 (con bibl.: 417). 
en nuestro caso infantil y juvenil, y provista de recursos para presentar aquellos años al lector con la fuerza, la gracia, el contraste, el colorido y los movimientos propios del celuloide ${ }^{147}$.

\section{2. ${ }^{\text {) }}$ Agustín, psicólogo}

No cabe duda que esta faceta es más importante que la anterior, aunque sea preciso advertir que la psicología también tiene que ver con el estilo. Una cosa es la doctrina y otra la forma. Si el estilo se preocupa más de la vestidura de la idea que de la misma idea, la psicología procede al revés, pero tampoco descuida la forma, desde luego. Agustín de Hipona, por ejemplo, refiere los hechos objetivos sólo en relación con procedimientos interiores, lo cual explica que mientras refiere algunos al detalle, con matices, otros que a primera vista lo merecerían más quedan silenciados o a lo sumo referidos de pasada. Algo se ha visto ya, pero insistamos.

Desde el punto de vista psicológico, el robo de las peras es de una importancia capital, en tanto que objetivamente no pasó de simple chiquillada ${ }^{148}$. El principio vale para otros textos pertenecientes a la época de adolescencia y juventud. La reacción ante determinadas circunstancias, el comportamiento de ésta o de aquella persona, el porqué de esta manera y no de la otra, la fina observación psicológica ante una u otra conducta y cien puntos más demuestran el gran interés que las actitudes del joven Agustín despertaban en la psicología del Pastor de Hipona ${ }^{149}$.

Una vez será abandonarse en los estudios por causa del juego ${ }^{150}$, otra definir el maniqueísmo con la capacidad seductora de la mujer procaz ${ }^{151}$, otra

147. Citando el estudio de M. VerheiJen (o.c., p. 143), sostiene Ch. Mohrmann que, a pesar de la variedad de estilo, «on peut dire que la dominante des Confessions est un style élevé à courtes phrases coupées, souvent antithétiques, ornées de jeux de sons. La parataxe y domine, le verbe est le plus souvent placés au début, l'usage d'un et, extrêmement fréquent, rattache les propositions en forme de parataxe ou introduit une phrase nouvelle et indédendante» (II, 260); A. TRAPE: BAC 422, p. 417.

148. Cf. A. Mandouze, Saint Augustin, 69-71; P. Brown, 223; F. De CAPITANI: LA/I, 108-119.

149. S. Vanni Rovighi, La psicologia di S. Agostino, Milano 1930; P. Vega Muñoz, Psicología de la conversión de san Agustín: Gr. 22 (1941) 9-24; 325-352; C. VACA, Puntos para una psicología del pecado en la Ciudad de Dios: CDios 167 (1958) 269-282; M. Pellegrino, Aspectos pedagógicos de las «Confesiones» de San Agustín: Augustinus 5 (1960) 55ss.; P. Brown, 206-239; V. CAPÁNAGa: BAC 10/I, Madrid 41969, 182-215 (bibl.: 717ss.); U. Del CAMPo Alonso, Proceso psicológico de la conversión religiosa de San Agustín, Roma 1972; cf. los estudios de S. Agostino educatore, Pavia 1971; y la bibl; de A. TRAPE: BAC 422, pp. 408-409; Ch. MoHrmanN, II, 277-292.

150. Conf. I, 10,16: «non enim meliora eligens inoboediens eram, sed amore ludendi» ( $\mathrm{p}$. 15); I, 9,15: «Non enim deerat, domine, memoria vel ingenium, quae nos habere voluisti pro illa aetate satis, sed delectabat ludere et vindicabatur in nos ab eis qui talia utique agebant» (p. 14).

151. Cf. nota 12 . 
las reacciónes infantiles en la escuela, mayormente a cuento del castigo y del temor ${ }^{152}$, otra la persistencia de los defectos en edad adulta ${ }^{153}$. Al capítulo de las definiciones concurren ese apretar o aflojar las riendas, que es un modo implícito de aludir a frenos y bridas, o sea al dominio y disciplina de la voluntad ${ }^{154}$. Y no digamos ya la influencia de malas compañías, de maestros sin escrúpulos y del juego a granel ${ }^{155}$, que empujan hacia la intemperancia y hacen, por ejemplo, que nuestro inquieto adolescente se enrole contento en la pandilla y desoiga, en cambio, las amonestaciones de la madre ${ }^{156}$.

Otro tanto cabe decir de la insatisfacción que las cosas pasajeras dejan en quien las disfruta ${ }^{157}$, o de la típica soberbia del intelectual que vuelve las espaldas a Dios ${ }^{158}$, o de cuáles suelen ser las esperanzas de los padres cuando mandan a sus hijos a estudiar ${ }^{159}$. Monumento admirable de psicología el de las Confesiones, incluso en el corto espacio biográfico que vengo analizando. $\mathrm{Si}$ el Medioevo llegó a ver en ellas una obra magnífica de meditación y los humanistas decimonónicos la autobiografía de uno de los más grandes pensadores de Occidente, en la actualidad brillan más como obra de análisis psicológico ${ }^{160}$. Gran servicio, pues, el que esta complicadísima y riquísima joya de la literatura ${ }^{161}$ puede rendir a todos los públicos, desde luego, pero especialmente a los jóvenes que se acerquen a sus páginas dispuestos a aprender de aquellos turbulentos años en los que el joven universitario Agustín, tan acompañado pero a la vez tan solo, pretendió resolver sus problemas desde la lejanía de Dios ${ }^{162}$.

152. Conf. I, 12,19-17,27. Cf. L.F. Pizzolato: LA/1, 46ss.

153. Cf. nota 47 .

154. Cf. nota 51 .

155. Cf. notas $58,74,75$ y 77 .

156. Cf. notas 71 y 74 .

157. Viene a ser la idea que le dejan al autor los hechos referidos en el libro II, y los primeros capítulos (llegada a Cartago, juegos, diversiones) del libro III de las Confesiones. El interrogante es pura elocuencia conclusiva: tales vita mea numquid vita erat, deus meus? (Conf. III, 2,4 , p. 47).

158. Cf. nota 104.

159. Dispuestos a privaciones como los que más por el futuro, intelectual especialmente, del hijo (Conf. II, 3,5; nota 80), con las esperanzas depositadas en su brillante carrera civil y poco más (II, 3,8; nota 81); por tanto, despreocupados en absoluto, como el padre de Agustín (II, 3,6; 3,8 , o no comprendiendo del todo, como la madre (II, 3,8; notas 82 y 84 ) las exigencias de la gracia.

160. «Si può dire che tra i fatti storici da una parte e l'elemento meditativo dall'altra c'è una larga zona, ch'è quella dell'autoanalisi psicologica, l'introspezione. I fatti storici obiettivi e l'analisi psicologica gli forniscono la materia della meditazione che finisce in una lode a Dion (MOHRMANN, II, 291; 292).

161. Cf. MohrmanN, II, 292, quien concluye así: «dipende dal lettore, dalla sua mentalità, dal suo proprio orientamento psicologico, dal suo temperamento la maggiore attenzione rivolta a questo o quell'elemento. Solo le grandissime opere letterarie sono quelle in cui ciascum lettore e, cosa più importante, ciascun tempo crede trovare ciò che più gli sta a cuore» (p. 292).

162. Solo, con la soledad que produce la ausencia de Dios, siendo así que «non enim longe 
3. a) Agustín, teólogo

Factum audivimus, mysreium requiramus (In Io 50,6): el lema predicacional es aplicable al epígrafe con el que quiero cerrar mi trabajo ya que la meta de los caminos literarios del Obispo de Hipona suele ser teológica ${ }^{163}$, como en esta etapa, por él analizada también «con santa humildad, con paz católica, con caridad cristiana» ${ }^{164}$, esa caridad que es «plenitud y fin de todas las Escrituras» ${ }^{165}$, y de la teología ${ }^{166}$, pues infunde ánimo al teólogo y para la teología es manantial de luz ${ }^{167}$.

La obsesiva preocupación del mal vertebra el libro II de las Confesiones ${ }^{168}$ y viene a ser igualmente el telón de fondo de casi todas las reflexiones teológicas de esta etapa ${ }^{169}$. Las parábolas del hijo pródigo y de la oveja perdida ponen de manifiesto que el prisma preferido del autor al analizar su infancia y juventud es, por encima de otros calificativos, teológico. Podrán admitirse las artes liberales, la poesía, el estilo, la psicología, la filosofía y la historia. No hay por qué negarlo. Pero en función teológica. El Santo prefirió contemplarse mirando a Dios y mirándose desde Dios: sub specie deitatis. De ahí el rigorismo de algunos juicios sobre su propia conducta ${ }^{170}$.

Se revela gran teólogo cuando define el pecado como un deleite en las vanidades ${ }^{171}$, un dejar de buscar a Dios y un buscar fuera de Dios ${ }^{172}$, un ante-

est a nobis omnipotentia tua, etiam cum longe sumus a te» (Conf. II, 2,3, p. 31). Soledad provocada por la algarabía de los hombres, de tal modo que «excesserunt caput meum vepres libidinum, et nulla erat eradicans manus» (Conf. II, 3,6, p. 33).

163. Cf. A. Trape: BAC 422, pp. 507-510; P. LANGA, San Agustín, Teólogo, 8ss., 13-20.

164. Cf. De bapt. II, 3,4 .

165. Cf. De d.chr. I, 35,39.

166. Cf. De d.chr. I, 3,3-40-44.

167. Cf. De q.an. 33,76 .

168. Sobre el problema del mal en términos generales, cf. R. JOLIVET, Le problème du mal d'après saint Augustin, Paris 1936; A. TRAPE: BAC 422, pp. 498-99 (abund. blib.: 501); G.R. Evans, Augustine on evil, Cambridge 1982. En las Confesiones, cf. G. MADEC: LA/III, Palermo 1985, 53ss.; y para Conf. II, cf. Burgaleta, 47-91, y espec. F. De Capitani, LA/I, Palermo $1984,108-119$.

169. No sólo por el dato biográfico y la constatación de haber amado ese mal, sino indirectamente: por las definiciones de pecado, y de Dios, y de las fuerzas dimanantes del mal o tendentes al mal. En respuesta a Evodio, puntualiza Agustín que «eam quaestionem moves, quae me admodum adulescentem vehementer exercuit et fatigatum in haereticos impulit atque deiecit» ( $D e$ lib.arb. I, 2,4). Cf. Burgaleta, 48ss.; F. De Capitani LA/I, 108ss.; A. Rigobello, Problema del male ed asistenza di Dio in Agostino, en: Linee per una antropologia prescolastica, Padova 1972, 29-43.

170. En cuanto al papel fundamental de la Escritura en la Teología, cf. A. TRAPE, I Padri e lo studio della teologia, en: Lo Studio dei Padri della Chiesa Oggi. I.P. Augustinianium, Roma 1977, 36-55:38ss.; Id., S. Agostino. L'uomo, 47-49; L.F. Pizzolato: LA/I, 9-30; P. LANGA, San Agustín, Teologo, 8ss.

171. Conf. $\mathbf{I}, 15,24$ : «et in eis vanis peccata delectationum mearum dimisisti mihi» (CSEL 33/1, p. 22); I, 20,31: «hoc enim peccabam, quod non in ipso, sed in creaturis eius me atque ceteras voluptates, sublimitates, veritates quaerebam» (p. 28); I, 13,22.

172. Conf. I, 20,31: «peccabam, quod non in ipso, sed in creaturis eius me atque ceteras voluptates... quaerebam» (p. 28). 
poner las criaturas ${ }^{173}$, un morir de alma ${ }^{174}$, una sordera y ceguera espirituales ${ }^{175}$, inmoderada inclinación ${ }^{176}$ hasta la fornicación y el adulterio del alma ${ }^{177}$. Discurre a lo teólogo, asimismo, cuando afirma que para disfrutar de la vida no es preciso alejarse de Dios ni transgredir su ley ${ }^{178}$.

Las definiciones de Dios escritas en estas páginas acreditan igualmente al sublime teólogo que el autor de las Confesiones llevaba dentro, comprendido el estupendo tratadista de la inhabitación trinitaria en el breve inciso alusivo a su madre: sed matris in pectore iam inchoaveras templum tuum et exordium sanctae habitationis tuae ${ }^{179}$.

También asoma el teólogo por el certero análisis del orgullo y de la soberbia, y de la perversión que acompaña al vicio ${ }^{180}$. Precisamente la razón que le movió a escribir las Confesiones ${ }^{181}$ encierra una excelente pastoral de auxilio

173. Conf. I, 13,22: «peccabam ergo puer, cum illa inania, istis utilioribus amore praeponebam vel potius ista oderam, illa amabam» (p. 20); II, 5,10: «...egrediendum abs te, ...deviandum a lege tua (...) peccatum admittitur, dum inmoderata in ista inclinatione, cum extrema bona sint, meliora et summa deseruntur» (p. 37); III, 3,5: «...amans vias meas et non tuas, amans fugitivam libertatem» (p. 47). Cf. notas 86,87 y 92 .

174. Cf. nota 46 .

175. Conf. II, 2,2: «obsurdueram stridore catenae mortalitatis meae» (p. 30); II, 2,2: «et obnubilabant atque obfuscabant cor meum» (p. 30); II, 3,7: «sed nesciebam et praeceps ibam tanta caecitate» (p. 34); III, 3,6: «tanta est caecitas hominum de caecitate etiam gloriantium» (p. 47); II, 2,3: «aut certe sonitum nubium tuarum vigilantius adverterem» (p. 31: aquí nubes = Apóstoles y S. Escritura, cf. De Gen.c.manich. II, 3,5; In ps. 56, 2,17).

176. Conf. II, 5,10: «...dum inmoderata in ista inclinatione...» (p. 37).

177. Conf. 1, 13,21: «non te amabam et fornicabar abs te (Ps 72,27) et fornicanti sonabat undique: 'euge', 'euge', amicitia enim mundi huius fornicatio est asb te et 'euge', 'euge' dicitur, ut pudeat, si non ita homo sit» (pp. 18-19). Y precisa cuándo fornica el alma: «Ita fornicatur anima, cum avertitur abs te et quaerit extra te ea quae pura et liquida non invenit, nisi cum redit ad te» (Conf. II, 6, 14, p. 40). Cf. HohrmanN, II, 16,238.

178. Conf. II, 5,10: «et tamen in cuncta haec adipiscenda non est egrediendum abs te, domine, neque deviandum a lege tua» (p. 37).

179. Conf. II, 3,6 (p. 33); I, 9,14: «auxilium et refugium meum» (p. 13); I, 13,20: «deus vita meai) (p. 18); I, 15,24: «ecce enim tu, domine, rex meus et deus meus (Ps 5,9), tibi serviat quidquid utile puer didici» (p. 22); I, 13,21: «deus, lumen cordis mei et panis oris intus animae meae et virtus maritans mentem meam et sinum cogitationis meae» (p. 18); $I 1,6,13$ : «...tu sis unus super omnia deus excelsus... unus et glóriosus in aeternum... tu omnia summe noveris... quid te autem innocentius?... quae vero quies certa praeter dominum?... tu es autem plenitudo et indeficiens copia incorruptibilis suavitatis... bonorum omnium largitor affluentissimus tu es... tu possides omnia... quid te excellentius?... te iustius quis vindicat?» (pp. 39-40); II, 6,12: «pulcherrime omnium, creator omnium, deus bone, deus summum bonum et bonum verum meum» (p. 38). Cf. notas 93-95.

180. Conf. II, 2,2: «obsurdueram stridore catenae mortalitatis meae, poena superbiae animae meae, et ibam longius a te, et sinebas, et iactabar et effundebar et diffluebam et ebulliebam per fornicationes meas, et tacebas» (p. 30); II, 3,7: «quid dignum est vituperatione nisi vitium? ego, ne vituperarer, vitiosior fiebam» (p. 34); III, 3,5: «vagatus sum praefidenti collo ad longe recedendum a te» (p. 47); III, 3,6: «et maior iam eram in schola rhetoris et gaudebam superbe et tumebam tyfo» (p. 47); III, 4,7: «...discebam libros eloquentiae, in qua eminere cupiebam fine damnabili et ventoso per gaudia vanitatis humanae» (p. 48).

181. Cf. nota 31 . 
y cercanía a los fieles, en este caso a los lectores de su obra, en la cual procura advertir de la tiranía de las pasiones y de las torpezas del pecado, o si el ejemplo lo requiere y el contraste lo pide, de las delicias que el alma experimenta cuando vive unida a Dios ${ }^{182}$.

Se revela, en fin, consumado teólogo al confiar ciegamente en la gracia, ya cuando matiza sobre la providencia divina que le ayudó a evitar males mayores ${ }^{183}$, ya desde la salud que en su opinión habría supuesto el recibir antes el bautismo y el matrimonio ${ }^{184}$.

El Augustinus ipse cum Augustino de esta crisis de lejanía y aversión se preocupa de subrayar a menudo - y ya es paradoja - la cercanía y la conversión a Dios ${ }^{185}$. Tres facetas, pues, en representación de otras muchas que podrían aducirse aquí para corroborar el mismo argumento. Sirvan ellas de síntesis y conclusión. La pedagogía agustiniana del período que acabo de exponer no sólo es digna de recuerdo por ser parte biográfica de un genio de la humanidad, sino que su carga aleccionadora hace que resulte muy actual, y yo diría que de interés permanente. Lo comprobará el lector si consulta, por ejemplo, los documentos de aquella reforma de vida que fue y sigue siendo ${ }^{186}$ el Concilio Vaticano II ${ }^{187}$.

PEDRO LANGA

Instituto Patrístico Augustinianum (Roma) Teologado Agustiniano Los Negrales (Madrid)

182. Conf. II, 5,10: «habent enim et haec ima delectationes, sed non sicut deus meus, qui fecit omnia, quia in ipso delectatur iustus, et ipse est deliciae rectorum corde» (p. 37). Cf. notas 88, 93-95.

183. Conf. II, 7,15: «diligam te, domine, et gratias agam et confitear nomini tuo, quoniam tanta dimisisti mihi mala et nefaria opera mea. Gratiae tuae deputo et misericordiae tuae, quod peccata mea tamquam glaciem solvisti» (pp. 40-41).

184. Cf. nota. 79.

185. Conf. II, 2,3: «non enim longe est a nobis omnipotentia tua, etiam cum longe sumus a te» (p. 31); II, 3,5: «neque enim tibi, deus meus, sed apud te narro haec generi meo» (p. 32); III, 4,7: «et surgere coeperam, ut ad te redirem» (p. 48); II, 10,18; passim.

186. Cf. Mensajes del Concilio a la Humanidad: $A$ los jovenes, 2: «Al final de esa impresionante 'reforma de vida' se vuelve (la Iglesia) a vosotros» (Concilio Vaticano II. Constituciones. Decretos. Declaraciones. BAC 252, Madrid 51967, 845). Y sobre el ateísmo: «fenómeno de cansancio y de vejez» (cf. Ib., p. 846). Digo que «sigue siendo» porque Juan Pablo II se propuso desde el principio de su pontificado llevar adelante lo determinado en el Concilio Vaticano II (cf.: Enseñanzas al Pueblo de Dios, -véase la nota 3-) y por ahí se pronunció igualmente el último Sínodo extraordinario de los obispos, con motivo de los veinte años de la clausura del Vaticano II.

187. Cf. J. MoRÁn, La presenza di S. Agostino nel Concilio Vaticano II: Augustinianum 6 (1966) 460-488. Sobre lo medular de la pedagogía agustiniana de este trabajo inciden no pocos textos del Vaticano II. Citaré dos al respecto, tomados de la declaración «Gravissimum educationis»: «Declara asimismo el sagrado Concilio que los niños y los adolescentes tienen derecho a que se les estimule a apreciar con recta conciencia los valores morales y a prestarles su adhesion personal, y tambièn a que se les incite a conocer y amar más a Dios» (GE, 1: BAC 252, pp. 810-811); y también: «este sagrado Concilio recuerda a los pastores de almas la obligación gravísima de disponerlo todo de forma que los fieles disfruten de la educación cristiana, y en primer lugar los jóvenes, que constituyen la esperanza de la Iglesia» (GE, 2: BAC 252, p. 812). 